\title{
Testosteron replasmanı ve kardiyovasküler yan etkileri
}

\section{Testosterone replacement and its cardiovascular side effects}

\author{
Ali Atan, Süleyman Yeșil, Fazlı Polat
}

\section{öz}

Testosteron (T), hipotalamus, hipofiz ve testis arasındaki bağlantı sonucu üretilen bir hormondur. T'un pek çok organ ve sistem üzerinde olumlu etkiler gösterdiği bilinmektedir. Bu faydalı etkilerine karşın, prostat ve kardiyovasküler sistem üzerinde bazı olumsuz etkiler oluşturduğu ile ilgili endişeler de vardır. T'un prostat kanseri ile olan ilişkisi son yıllarda yoğun olarak çalışılmış ve endojen $\mathrm{T}$ düzeyi ile $\mathrm{T}$ replasman tedavisinin prostat kanseri oluşumunda bir etkisinin olmadığı gösterilmiştir. Bu derlemede, mevcut uluslararası literatür gözden geçirilerek, T'un kardiyovasküler sistem üzerindeki etkileri sunulmaktadır.

Anahtar Kelimeler: Testosteron, kardiyovasküler sistem, yan etki
T estosteron (T) hipotalamus, hipofiz ve testis arasındaki bağlantı sonucu üretilen bir hormondur. Hipotalamustan pulsatil olarak salınan gonadotropin salgılatıcı hormon $(\mathrm{GnRH})$ ön hipofizden luteinizan hormon (LH) salınımını sağlayarak testislerin Leydig hücrelerinin $\mathrm{T}$ üretmesini sağlar. Testislerden üretilen T, dolaşımdaki T'nin \%95’ten fazlasını oluşturur. ${ }^{[1]}$ Serumdaki normal T düzeyi için alt sınır 350 ng/dL'dir. T, 20-30 yaş aralığındaki erkeklerde en yüksek düzeylerdedir. Yaş ile T düzeyinin azaldığı bilinen bir durum olmasına karşın değişik çalışmalarda farklı düzeylerde T azlığı saptanmıştır. Kaufman ve Vermeulen'in çalışmasında 60 yaş sonrası erkeklerin yaklaşık \%20'sinde $\mathrm{T}$ normal düzeyin altında olduğu bulunmuştur. ${ }^{[2]}$ Başka çalışmalarda ise 45 yaş üzeri erkeklerin \%12-38'inde T azalmasının olduğu saptanmıştır. ${ }^{[3,4]}$

\section{Gazi Üniversitesi, Tıp Fakültesi, Üroloji Anabilim Dalı}

Yazışma Adresi / Correspondence:

Prof. Dr. Ali Atan

Birlik Mahallesi, 396 sokak, 14/11, Çankaya, Ankara - Türkiye

Tel. $\quad+905324242082$

E-mail: aliatanpitt@hotmail.com

Geliş / Received: $\quad$ 26.03.2017

Kabul / Accepted: 03.05.2017

\section{ABSTRACT}

Testosterone $(\mathrm{T})$ is a hormone produced by the connection between the hypothalamus, pituitary and testis. It is known that $\mathrm{T}$ has positive effects on many organs and systems. In spite of these beneficial effects, there are concerns about some adverse effects on the prostate and cardiovascular system. The association of $\mathrm{T}$ with prostate cancer has been intensively studied in recent years and it has been shown that endogenous T levels and T-replacement therapy have no effect on prostate cancer formation. In this review, we present the effects of $\mathrm{T}$ on the cardiovascular system by reviewing the current international literature.

Keywords: Testosteron, cardiovascular system, side effect

T genelde genital organlar ve cinsel fonksiyonlar üzerinde etkili bir hormon olarak bilinmesine karşın, deri, karaciğer, beyin, adale, böbrekler, kemik ve kemik iliği üzerinde de çeşitli etkileri vardır. $T$ periferde bu etkilerini bizzat $T$ olarak yapmakla beraber bir prohormon olarak da oluşturur. T, 5-alfa redüktaz enzimi yoluyla dihidrotestosterona (DHT) ve aromataz enzimi yoluyla östradiole dönüşerek etkilerini ortaya koyar. ${ }^{[1]}$ Yapılan klinik çalışmalarda T'nin kuvvetli kanıtlarla libidoyu, ereksiyon fonksiyonunu, kemik mineral dansitesini, adale kitlesini ve adale gücünü, hematopoezi arttırdığı, yağ kitlesini azalttığı, zayıf kanıtlarla kardiyovasküler sistem, ruh hali, bilişsel fonksiyonlar, enerji düzeyi ve insülin duyarlılığı üzerinde olumlu etkisinin olduğu saptanmıştır. Ancak ekzojen T'nin sadece spermatogenez üzerinde kuvvetli kanıtlarla olumsuz etkisi olduğu gösterilmiştir. ${ }^{[1]}$ Fayda ve zarar açısından bakıldığında, T'nin Kanıt 1 verilerle faydalı olduğu belirtilmektedir. Buna rağmen T ile ilgili hala endişe duyulan iki önemli konu vardır. Bunlar T'nin prostat kanseri ile olan ilişkisi ve T'nin kardiyovasküler yan etkileridir. T'nin prostat kanseri ile olan ilişkisi son yıllarda yoğun olarak çalışılmış ve endojen $T$ düzeyi ile $T$ replasman tedavisinin prostat kanseri oluşumunda bir etkisinin olmadığı gösterilmiştir. ${ }^{[5]}$ Günümüzde araştırılan ve henüz tam olarak açıklığa kavuşmamış olan konu, T’nin kardiyovasküler sistem üze- 
rindeki yan etkileridir. Bu derlemede, mevcut uluslararası literatüre bakarak T'nin kardiyovasküler sistem üzerindeki etkileri incelenmektedir.

Uluslararası literatürde, T’nin kardiyovasküler sistem üzerinde zararlı olduğunu belirten çalışma sayısı sınırlıdır. ${ }^{[6-10]}$ İlk çalışma randomize, plasebo kontrollü bir çalışmadır. T jel ile plasebo karşılaştırılmıştır. Çalışmanın amacı, sınırlı mobilitesi olan 65 yaş üzeri erkeklerde fiziksel fonksiyonların ve alt ekstremite gücünün değerlendirilmesidir. $\mathrm{T}$ tedavisi ile adale gücünde artış saptanmasına karşın $\mathrm{T}$ grubunda $\% 23$, plasebo grubunda $\% 5$ kardiyovasküler yan etkiler saptanmıştır. Yüksek kardiyovasküler yan etkilerden dolayı çalışma erken bırakılmıştır. Ancak, çalışma kardiyovasküler yan etkileri saptama amacıyla planlanmamıştır. Çalışmayı bırakma nedeni olan kardiyovasküler yan etkiler, genelde ciddi (çarpıntı, pedal ödem, EKG'de prematür ventriküler kasılmalar, hipertansiyon, taşikardi) olmadığı belirtilmektedir. Çalışmaya alınan kişilerde, tedavi öncesi kardiyovasküler hastalık durumu ve risk faktörleri bilinmemektedir. Ayrıca diğer T formülasyonları ve dozları ile ilgili genel bir kanaat verilmesi uygun değildir. ${ }^{[6]}$ İkinci çalışma, retrospektif bir çalışmadır. ${ }^{[7]} \mathrm{T}$ tedavisi alan ve almayan hipogonadal yaşlı erkekler inme, miyokard enfraktüsü ve ölüm açısından değerlendirilmiştir. $T$ tedavisi grubunda $\% 25,7, \mathrm{~T}$ almayan grupta \%19,9 oranında kardiyovasküler yan etkilerin meydana geldiği belirtilmiştir. Ancak, yazarlar daha sonra makaleleri ile ilgili iki defa düzeltme yapma talebinde bulunmuşlardır. Bu düzeltme gayretlerine rağmen çalışma grubunun \%10'unun kadınlardan oluştuğu saptanmıştır. Çalışma düzeni, yöntem ve değerlendirme hataları olduğu gösterilmiştir. Veriler doğru olarak değerlendirildiğinde yan etkiler $\mathrm{T}$ tedavisi grubunda \%10,1, diğer grupta \%21,2 bulunmuştur. ${ }^{[11]} \mathrm{Bu}$ hatalar nedeniyle, 29 tıp derneği makalenin akademik ortamdan çekilmesi gerektiğini savunmaktadır. ${ }^{[12,13]}$ İlaç firmalarının desteklemediği 27 plasebo kontrollü T tedavisi çalışmasının değerlendirildiği bir meta-analizde, kardiyovasküler yan etkiler değerlendirilmiştir. İncelenen 27 çalışmanın iki tanesinin tüm kardiyovasküler yan etkilere katkı oranı \%35 olarak saptanmıştır. ${ }^{[6,14]}$ Basaria ve arkadaşlarının çalışması ile ilgili eleştiriler önceden belirtilmiştir. Diğer çalışmada, onaylanmamış bir oral $T$ formülasyonu oldukça yüksek bir dozda (600 mg/gün) kullanılmıştır. Serum T düzeyi normalin 20 katına çıkmıştır. Anlatılan nedenlerle bu meta-analizin sonuçlarının çok güvenilir olmadığı düşünülmektedir. Ayrıca bahsedilen iki çalışma hariç tutulduğunda $T$ ve plasebo grubunda kardiyovasküler yan etkiler benzerdir. T grubunda 1599 erkekte 78 yan etki $(\% 4,88)$, plasebo grubunda 1174 erkekte 60 yan etki $(\% 5,1)$ saptanmıştır. ${ }^{[8]}$ Sigorta şirketi verilerine göre yapılan retrospektif bir analizde ise
T tedavisi sonrası 90 günlük dönemde görülen kardiyovasküler yan etkiler tedavi öncesi 12 aylık dönem ile karşılaştırılmıştır. T tedavisi sonrası fatal olmayan kardiyovasküler yan etkilerde \%36 artış saptanmıştır. Ancak, kontrol grubu yoktur ve bu iki periyodun karşılaştırılması uygun değildir. [9] Son olarak, farklı $\mathrm{T}$ formu alan kişilerde kardiyovasküler yan etkiler incelenmiştir. Enjeksiyon formunun jel ve yamalara göre en fazla yan etkiyi oluşturduğu saptanmıştır. Ancak bu, kontrol grubu olmayan bir çalışmadır. ${ }^{[10]}$

Güncel verilerin çoğunluğunda $T$ replasman tedavisinin kardiyovasküler sistem üzerinde faydalı olduğu belirtilmektedir. ${ }^{[1,5,12,13,15-19]}$ Corona ve arkadaşlarının yaptığ 1 Tip 2 Diabetes mellitus ve metabolik sendromu bulunan kişilerin de dahil olduğu 75 çalışmanın meta-analizinde, $T$ tedavisinin kardiyovasküler yan etkilere yol açmadığı ve hatta koruyucu etki oluşturduğu belirtilmektedir. ${ }^{[17]}$ Kardiyoloji, üroloji ve endokrinoloji uzmanlarının ortak yazdığı çok yeni bir derleme makalede, T'nin kardiyak etkileri incelenmiştir. Bu derlemede, T’nin endotel üzerindeki etkisi ile vazodilatasyon yaparak periferik ve koroner kan akımını arttırdığı, sistemik vasküler direncin ve sol ventrikül diastol sonu basıncının azalması sonucu kardiyak atımı arttırdığ1, kardiyovasküler enflamasyon ve ateroskleroz belirteçleri üzerine anlamlı bir etkisinin olmadığı, kardiyak iletim üzerinde depolarizasyon esnasinda ve hemen sonrasinda aksiyon potansiyelini azaltarak Q-T aralığını kısalttığı ve anti-aritmik bir etki oluşturduğu, lipit düzeyleri üzerine anlamlı bir etkisinin olmadığı, miyokard üzerinde STAT3 (Signal Transducer and Activator of Transcription-3) aktivasyonu ile reperfüzyon hasarını azalttığı, aterom oluşumu üzerinde net bir etkisinin bulunmadığı, sadece tromboksan A-2 reseptör aktivasyonu ile trombosit agregasyonunu arttırarak tromboz riskini arttırdığı belirtilmektedir. ${ }^{[1]}$ Morgantaler ve arkadaşlarının yaptıkları 1940 ile 2014 yılları arasında "testosteron, androjenler, insan, erkek, kardiyovasküler, inme, serebrovasküler olay, miyokardiyal enfarktüs, kalp krizi, ölüm ve mortalite” anahtar kelimeleri ile yapılan Medline taraması sonucu ulaştıkları makalelerin bir derlemesinde, $\mathrm{T}$ tedavisinin mortalite, koroner arter hastalığı sıklığı, koroner arter hastalığı ciddiyeti, karotis intima-media kalınlığı, obezite/yağ kitlesi, lipit profili, glisemik kontrol, enflamatuar belirteçler (CRP, TNF-alfa) ve kalp yetmezliği ile ilişkisi incelenmiştir. Elde edilen kanıtlar değerlendirilmiş ve kanıt düzeyleri saptanmıştır. Bu derlemede, total, biyo-aktif ve serbest T'nin düşük düzeylerinin kardiyovasküler ve tüm nedenlere bağlı mortalite için risk artışına neden olduğu (kanıt düzeyi 2a); total, biyo-aktif ve serbest T'nin düşük düzeylerinin gizli koroner arter hastalığı ile ilişkili olduğu (kanıt düzeyi 2a); total, biyo-aktif ve serbest $\mathrm{T}$ düzeylerinin koroner arter hastalığı ciddiyeti 
ile ters orantılı olduğu (kanıt düzeyi 2a); total, biyo-aktif ve serbest $T$ düzeylerinin karotis intima-media kalınlığının ve/veya karotis plak volümü ile ters korelasyonlu olduğu (kanıt düzeyi 2a); T tedavisinin obezite ve yağ kitlesinde anlamlı azalma ile ilişkili olduğu (kanıt düzeyi $1 \mathrm{~b}$ ); T tedavisinin total kolesterol, HDL ve LDL düzeylerinde küçük azalmalara yol açtığı ancak trigliserid düzeyleri üzerinde anlamlı bir etkisinin olmadığı (kanıt düzeyi $2 \mathrm{a}$ ); $\mathrm{T}$ tedavisinin diyabetik ve pre-diyabetik erkeklerde serum glukoz düzeyinde, hemoglobin A1c düzeyinde ve insülin direncinde azalma yaptığı (kanıt düzeyi 1a); T tedavisinin enflamatuar belirteç düzeylerinde devamlılık göstermeyen bir azalma ile ilişkili olduğu (kanıt düzeyi 1b); T tedavisinin egzersiz ile semptomatik anjina başlamasını geciktirdiği (kanıt düzeyi 1b); T tedavisinin semptomatik konjestif kalp yetmezliği olan erkeklerde egzersiz kapasitesini arttırdığ 1 ve oksijen tüketimini düzelttiği (kanıt düzeyi 1a) saptanmıştır. ${ }^{[13]}$

Kurumsal anlamda ise bu konuya yaklaşım net değildir. Amerikan Gıda ve İlaç Kurumu, 2014 ve 2015 yıllarında bazı açıklamalarda bulunmuştur. İlk olarak, Eylül 2014 yılında $T$ tedavisinin kullanımı ve $T$ tedavisinin kardiyovasküler risklerini incelemek üzere bir tavsiye komitesi toplamıştır. Komiteden, $T$ tedavisinin güncel endikasyonları konusunda görüş vermeleri ve $T$ üreticilerinden $T$ kullanımı ile ilgili kardiyovasküler riskleri saptamak için çalışmalar yapmaları istenmiştir. Komite üyeleri, $\mathrm{T}$ tedavisi almış hastalarda anlamlı bir kardiyovasküler risk oluşturduğu konusunda yeterli kanıtların olmadığı sonucuna varmışlardır. Bununla birlikte komite, yaşlı, diyabetik ve obezite gibi yüksek kardiyovasküler riski olan kişilerde $\mathrm{T}$ tedavisinin emniyeti için daha ileri çalışmalara gerek olduğunu vurgulamıştır. Daha sonra Mart 2015'te Amerikan Gıda ve İlaç Kurumu, T tedavisi kullanımı ile ilgili önerilerini netleştirmiş ve $\mathrm{T}$ tedavisinin sadece özel tıbbi durumlara bağlı dökümante edilmiş $T$ düşüklüğü olan erkeklerde onaylandığını beyan etmiştir. Komite ayrıca, semptomatik olsa bile, T'u düşük yaşlı erkeklerde T tedavisinin faydaları ve emniyetinin açık olmadığını da ifade etmiştir. Son olarak Haziran 2015'te Amerikan Gıda ve İlaç Kurumu, T ürünü üreticilerinin prospektüslere ilave uyarılar içerecek şekilde değişiklik yapmalarının gereğini belirtmiştir. ${ }^{[20,21]}$ Amerikan Gıda ve İlaç Kurumu’nun aksine, Amerikan Klinik Endokrinologları Derneği ve Amerikan Endokrinoloji Kolejinin ortak konsensüs raporunda, $T$ tedavisinin kardiyovasküler riski arttırdığına dair anlamlı deliller olmadığı beyan edilmektedir. ${ }^{[22]}$

\section{SONUÇ}

Sonuç olarak, Kloner ve arkadaşlarının derlemesinde ifade edildiği gibi ${ }^{[1]}$, mevcut verilere göre genç ve sağlıklı hipo- gonadal erkeklerde $T$ tedavisinin endişe nedeni olmadığı, asemptomatik, 40-65 yaş arasında ve kalp hastalığı öyküsü olmayan erkeklerde ise kardiyovasküler riskler anlatılarak $\mathrm{T}$ tedavisinin verilebileceği, ancak yaşlı ve bilinen koroner arter hastalığı olan erkeklerde $T$ tedavisi kullanımının tartışmalı olduğu, son altı ayda miyokard enfarktüsü geçirmiş, revaskülarizasyon yapılmış, kötü kontrollü konjestif kalp yetmezliği bulunan ve inme öyküsü olan erkeklerde ise $T$ tedavisinin uygun olmadığı söylenebilir.

Hakem Değerlendirmesi

Dış bağımsız

\section{Çıkar Çatışması}

Yazarlar çıkar ilişkisi olmadığını beyan etmişlerdir.

\section{Peer-review}

Externally peer-reviewed.

\section{Conflict of Interest}

No conflict of interest was declared by the authors.

\section{KAYNAKLAR}

1. Kloner RA, Carson C 3rd, Dobs A, Kopecky S, Mohler ER 3rd. Testosterone and Cardiovascular Disease. J Am Coll Cardiol 2016;67:545-57. doi: 10.1016/j.jacc.2015.12.005

2. Kaufman JM, Vermeulen A. The decline of androgen levels in elderly men and its clinical and therapeutic implications. Endocr Rev 2005;26:833-76. doi: 10.1210/er.2004-0013

3. Mulligan T, Frick M, Zuraw QC, Stemhagen A, McWhirter C. Prevalence of hypogonadism in males aged at least 45 years: the HIM study. Int J Clin Pract 2006;60:762-9. doi: 10.1111/j.17421241.2006.00992.x

4. Dhindsa S, Miller MG, McWhirter CL, Mager DE, Ghanim H, Chaudhuri A, et al. Testosterone concentrations in diabetic and nondiabetic obese men. Diabetes Care 2010;33:1186-92. doi: 10.2337/dc09-1649

5. Morgentaler A. Controversies and Advances with Testosterone Therapy: A 40-Year Perspective. Urology 2016;89:27-32. doi: 10.1016/j.urology.2015.11.034

6. Basaria S, Coviello AD, Travison TG, Storer TW, Farwell WR, Jette AM, et al. Adverse events associated with testosterone administration. N Engl J Med 2010;363:109-22. doi: 10.1056/ NEJMoa 1000485

7. Vigen R, O’Donnell CI, Barón AE, Grunwald GK, Maddox TM, Bradley SM, et al. Association of testosterone therapy with mortality, myocardial infarction, and stroke in men with low testosterone levels. JAMA 2013;310:1829-36. doi: 10.1001/ jama.2013.280386

8. Xu L, Freeman G, Cowling BJ, Schooling CM. Testosterone therapy and cardiovascular events among men: a systematic review and metaanalysis of placebo-controlled randomized trials. BMC Med 2013;11:108. doi: 10.1186/1741-7015-11-108

9. Finkle WD, Greenland S, Ridgeway GK, Adams JL, Frasco MA, Cook $\mathrm{MB}$, et al. Increased risk of non-fatal myocardial infarction following testosterone therapy prescription in men. PLoS One 2014;9:e85805. doi: 10.1371/journal.pone.0085805

10. Layton JB, Meier CR, Sharpless JL, Stürmer T, Jick SS, Brookhart MA. Comparative Safety of Testosterone Dosage Forms. JAMA Intern Med 2015;175:1187-96. doi: 10.1001/ jamainternmed.2015.1573 
11. Traish AM, Guay AT, Morgentaler A. Death by testosterone? We think not! J Sex Med 2014;11:624-9. doi: 10.1111/jsm.12464

12. Morgentaler A, Lunenfeld B. Testosterone and cardiovascular risk: world's experts take unprecedented action to correct misinformation. Aging Male 2014;17:63-5. doi: 10.3109/13685538.2014.913413

13. Morgentaler A, Miner MM, Caliber M, Guay AT, Khera M, Traish AM. Testosterone therapy and cardiovascular risk: advances and controversies. Mayo Clin Proc 2015;90:224-51. doi: 10.1016/j. mayocp.2014.10.011

14. The Copenhagen Study Group for Liver Diseases. Testosterone treatment of men with alcoholic cirrhosis: a double-blind study. Hepatology 1986;6:807-13.

15. Shores MM, Smith NL, Forsberg CW, Anawalt BD, Matsumoto AM. Testosterone treatment and mortality in men with low testosterone levels. J Clin Endocrinol Metab 2012;97:2050-8. doi: 10.1210/jc.2011-2591

16. Muraleedharan V, Marsh H, Kapoor D, Channer KS, Jones TH. Testosterone deficiency is associated with increased risk of mortality and testosterone replacement improves survival in men with type 2 diabetes. Eur J Endocrinol 2013;169:725-33. doi: 10.1530/EJE13-0321

17. Corona G, Maseroli E, Rastrelli G, Isidori AM, Sforza A, Mannucci E, et al. Cardiovascular risk associated with testosterone-boosting medications: a systematic review and meta-analysis. Expert Opin Drug Saf2014;13:1327-51. doi: 10.1517/14740338.2014.950653

18. Corona GG, Rastrelli G, Maseroli E, Sforza A, Maggi M. Testosterone Replacement Therapy and Cardiovascular Risk: A Review. World J Mens Health 2015;33:130-42. doi: 10.5534/ wjmh.2015.33.3.130
19. Hackett G. An update on the role of testosterone replacement therapy in the management of hypogonadism. Ther Adv Urol 2016;8:147-60. doi: 10.1177/1756287215617648

20. Bhatt K, Johnson J. Summary Minutes of the Joint Meeting of the Bone, Reproductive and Urologic Drugs Advisory Committee and the Drug Safety and Risk Management Advisory Committee Meeting, September 18, 2014. U. S. Food and Drug Administration, Center for Drug Evaluation and Research. Available at: https:// wayback.archive-it.org/7993/20170113050249/http://www. gov/ downloads/AdvisoryCommittees/CommitteesMeetingMaterials/ Drugs/ReproductiveHealthDrugsAdvisoryCommittee/ UCM424069.pdf Accessed December 2, 2015.

21. U. S. Food and Drug Administration 2015. FDA Drug Safety Communication: FDA cautions about using testosterone products for low testosterone due to aging; requires labeling change to inform of possible increased risk of heart attack and stroke with use. Available at: https://www.fda.gov/Drugs/DrugSafety/ucm436259. htm Accessed December 2, 2015.

22. Goodman N, Guay A, Dandona P, Dhindsa S, Faiman C, Cunningham GR; AACE Reproductive Endocrinology Scientific Committee. American Association of Clinical Endocrinologists and American College of Endocrinology Position Statement of the Association of Testosterone and Cardiovascular Risk. Endocr Pract 2015;21:1066-73. doi: 10.4158/EP14434.PS 